\title{
GAMIFICATION STRATEGIES IN HIGHER EDUCATION: LEVERAGING PAST IN THE ERA OF PANDEMIC
}

\author{
Anil Yasin Ar \\ International Business Department, Tecnologico de Monterrey, Mexico
}

\begin{abstract}
The on-going pandemic has shifted how education, teaching strategies, and technology interact with each other. With the universities forced by the COVID-19 to cease on-campus education and immigrate to virtual class settings, virtual tools, once perceived as a supporting or supplementary education aspect, evolve to be the center stone of contemporary education. While vast arrays of rearrangements are taking place and new ways of class delivery styles are experimenting, the need for providing an engaging online content delivery strategy still exists. As a result, to support a dynamic teaching structure and achieve desired learning outcomes, some university and college lecturers start to employ non-traditional teaching techniques. One of the most widely used and relatively controversial techniques that emerged as a solution is gamification. Whether this teaching method is effective or not has not been well established. It is also still questionable how this strategy can be utilized in a virtual learning environment. Motivated to contribute this on-going debate, the present paper proposes to conduct a systematic literature review following the "Preferred Reporting Items for Systematic Reviews and Meta-Analyses" (PRISMA) methodology to answer the following set of questions: (1) Is gamification a viable teaching strategy? (2) What are the commonly used gamification strategies? (3) Can gamification-based teaching be incorporated to online classes? This study utilizes the Web of Science (WoS) Core Collection database to mine data for the last five years to answer research questions. The results indicate that gamification is an effective teaching strategy and can be easily integrated into virtual class settings. Findings contribute to the relevant literature strand while providing insight about contemporary teaching styles to lecturers.
\end{abstract}

Keywords: gamification, PRISMA, educational innovation, higher education, COVID-19

\section{Introduction}

Innovations in communication technologies (ICT) and globalization transform how societies and firms view higher education graduates (Nolan \& Hunter, 2012). The demand for softskills and critical thinking are in the core of these changes, the expectations from higher education pupils evolved from conducting highly sofisticated tasks to ability to function across cultures, disciplines, and structures (Lewis, 2017). They are expected to be act as a catalyst of positive and responsible change, while innovating to solve critical problems of the societies that they are living and supporting economic development (Ames et al, 2017; Ahern et al (a), 2019).

Consequently, the altered expectations mandate the educational programs to evolve. As a response, the delivery of the content in and out of the classroom has been iterated under an array of subjects, such as, curriculum design, developing new institutional policies, and industry partnerships (Lane, 2015; Zhang et al., 2017). As Kotter (1996) states that any change at an institution would mean moving from known to unknown higher education institutions and academics involve with the 
arduous work of finding new methodologies that could not only be affective but also can be easily adaptable.

For instance, the new higher education models envisage the prevailing learning systems as a tool that grounds theoretical learning and real-world examples at a collaborative class environment (Ahern et al (a), 2019; Ahern et al (b), 2012). In other words, expertise area knowledge must be reinforced by interdisciplinary and inter-personal skills centered pedagogic methodologies (Ahern et al (a), 2019; Ahern et al (b), 2012; Naimpally et al., 2012). Such a shift from classical education style to more contemporary style requires a thorough strategizing of education tools. Higher education leaders, educators and lecturers must be cautious outlining the borders concerning appropriate pedagogic approaches while offering interactive learning tools to supplement practical education processes.

The main constraints that higher education professionals are facing in terms of aforementioned pedagogic challenge are ability to balance theoretical framework that imparts theory and a practical standpoint that commences hands-on trainings (Alomari et al., 2019). Inability to balance these standpoints and lenience towards one side over the other could threaten a desired level of learning outcome for higher education pupils. In the case of the theory intensive programs, students would regress in their development of practical competencies as a consequence of passive learning. On the contrary, if the hands-on learning or practical side prevails over the theoretical side of a higher education program, pupils would be stagnant on their theoretical development level in their respective areas of expertise.

In order to counter the mentioned problem and implement a strategy that could answer the needs of the current trends, many higher education institutions start experimenting with the gamification strategies in their programs (Oliver, 2017). Studies has shown that it can be an effective tool to support deep-learning, inter-disciplinary critical thinking, peer-based learning, and intrinsic motivation (Treiblmaier \& Putz, 2020). Yet, it is not clear how to implement this tool to dramatically changed landscape of higher education due to the on-going pandemic.

The absence of clear directions for how to translate in-class dynamics into virtual classes created a new challenge for the higher education institutions (Kamsker et al., 2020; Sasere \& Makhasane, 2020). Before they tackle the change in stakeholders' expectation, these institutions are challanged by the implimentation of new education system that satisfies the expectations of students and diverse bodies while enabling academics to deliver high quality through online or hybrid classes. Students and lecturers alike forced to develop new skills to stay relevant to online and hybrid courses, and the institutions are put into position to decide how to address these needs (Kamsker et al., 2020).

Based on the above discussion, the present paper investigates the following set of questions: (1) Is gamification a viable teaching strategy? (2) What are the commonly used gamification strategies? (3) Can gamification-based teaching be incorporated to online classes? In order to tackle task in the hand, it utilizes the "Preferred Reporting Items for Systematic Reviews and Meta-Analyses" (PRISMA) methodology. This enables the study to survey the body of relevant literature to observe what type of strategies have been implemented in higher education in terms of gamification that can be useful in higher education today, during and after the pandemic.

The rest of the article is arranged as follows. In the following section, the paper presents gamification and gamification related conceptual background and framework. Then, it offers insight about the 
methodology employed for the paper and why it is implemented. At the final two sections, the paper draws conclusion via utilizing PRISMA results and offers directions for future research.

\section{Contextual Background}

On average, at a given expertise area, a technical knowledge and know-how would be transformed and become passé or absolute in five to seven years (Naimpally et al., 2012). As Eggers et al. (2012) states, a learned information could even be transformed into a new idea before students finish paying their tutions debts. High school pupils, thus, must be offered instruments which could assist them in their education goals, workplace as well as professional adaptation. These necessitates institutions to leverage non-traditional learning methodologies, which revolutionize passive learning and offers unique way of learning engagement in new teaching paradigms (Berryman et al., 2013; World Economic Forum, 2017).

Not being able to depart from traditional teaching method is one of the biggest struggles of the higher education (DeMillo, 2015; Mainon, 2018). Many universities still strugling deviating from lecture base, the very rudemental and traditional teaching method, to more dynamic and contemporary teaching methods that could help building higher quality cirriculums (Zemsky \& Banning, 2013). This struggle stems from either financial burden that comes with the ability to support such changes (Bradley et al, 2011; Lane, 2015), lack of ability to build institutional competencies (Zemsky \& Banning, 2013; Ruano-Borbalan, 2019) or combination of them. Therefore, the innovative, yet easily adaptable new teaching styles that would support the prerequisites of modern higher education systems are needed.

One of the candidates that could solve this multifacated problem is the gamification. Gamification, in the simplest terms, can be define as utilizing game dynamics in the context of educational doctorine (Panis et al., 2020). It leverages ICT developments to create an interactive learning base while utilizing game dynamics to motivate students to participate in-class activities and interact with their peers (Vanduhe et al., 2020). In addition, gamification supports the flip-class structure and further reimbursts the in-class teachings with real-world-alike experiences (Sailer \& Sailer, 2021). This creates a better learning environment further supports to a deep learning state (Aguiar-Castillo et al., 2020).

Deep learning state is described as the linking process of ex-ante knowledge to a new conceptual knowledge while building new skills that can be applicable into real life scenarios (Karkoub et al, 2020). It differs from traditional learning environment in the sense that it replaces uni-dementional knowledge acquiring to multi-dementional sense making and transformative skill building (ArcherKuhn et al., 2020). It enables students to interact with their peers to learn new perspectives through diverse ideas and increase their soft-skill advancement pace, which are essential to contemporary business environment (Bakhanova et al, 2020).

Another advantage of utilizing gamification method of teaching is ability to convert traditional learning dynamics to digitalized multi-access platforms, where interaction is not limited to turn base, but simultaneous and instantenous (Lizandra et al., 2020). It enhances the student and instructor interaction via providing different layers of engagement and communication paths (Bai et al., 2020). However, some researchers suggest that the current phase and the way that gamification is applied to higher education is superficial as well as inadequate (Bogost, 2011; Toda et al., 2018). They believe 
that gamification oversimplifies reality and lead to lesser learning outcomes and stagnation among pupils. On the contrary side, the contemporary research provided strong evidence suggesting appropriate choice of gamification strategy could eradicate the mentioned problems and further enhance important educational consequences, such as, improved self-perceived competencies, collaborative problem solving, and higher aptitude towards theoretical subjects (Tsay et al., 2018; Jurgelaitis, 2019; Klock et al, 2020).

During the time of pandemic and transformation from on campus learning to online learning, beyond the capability of providing a teaching tool, gamification could also be utilized as an assessment tool in digital settings. For instance, it is possible to utilize game concepts to first deliver the content at a given class, then, utilizing gamification techniques to measure the learning outcome (Kapp et al, 2013). Connectivist pedagogy perspective, "the connectedness of learners through electronic networks" (Danka, 2020. p.76), highlights that self-teaching, lifelong learning as well as peerinteraction and evaluation of learning can be possible via leveraging gamification strategies (Xiong \& Suen, 2018; Sezgin \& Sezgin, 2019; Danka, 2020).

Yet, there are not a consensus on strategies which could yield desirable outcome as oppose to jeopardize integrity of curriculum building and program development. In order to fill this gap, the following set of research questions are investigated: (1) Is gamification a viable teaching strategy? (2) What are the commonly used gamification strategies? (3) Can gamification-based teaching be incorporated to online classes? The next section of the study introduces how "Systematic Reviews and Meta-Analyses" (PRISMA) methodology is employed in the context of this study.

\section{Methodology}

The majority of the methodical examinations of literature in the education disciplines have adopted either narrative literature review, metamethod review, thematic review, or meta-analytic trend analysis (Hallinger, 2013). However, these methods might either suffer from academic rigor to explain essence of the focused topic or disregard major studies' discoveries (Levitt, 2020; Moher et $a l, 2009)$. Thus, to address these concerns and supplement the robustness of the study, this systematic review employs a mix of inductive and deductive strategy, namely PRISMA method.

PRISMA method, classified as a qualitative research approach, utilizes a flow chart scheme which reflects upon each stage of a methodical and systematic literature review (Moher et al, 2009; Wang et al., 2020). The inferential strategy is employed to craft steps of the systematic review, such as, search engine selection, quality appraisal, analysis, and inclusion, and exclusion criteria based on previous researches (Mertz et al., 2017). In a similar fashion, inductive approach is applied to advance the quality and refinement of selected papers. As a last refinement point, the author go through the "abstract," "introduction," "methodology," and "conclusion" sections of the selected papers. This enables the study to highlight efficacy of relevant literature while addressing the aforementioned research questions.

\section{Data \& PRISMA Application}

Web of Science (WoS) Core Collection is chosen as a data source. It was utilized to conduct research with the data range "last five years." As a rule of thumb and exclusion criteria, documents that are either identified as literature review, editorial entries, book chapters, work in progress, reprint, early 
access or conference presentations and proceedings are omitted. Only full scholarly papers that are published by the time February 10th, 2021, are considered. In addition, any papers that is not openaccess and not written in English is omitted. These criteria are established based on the previous literature to increase the transparency of the study while ensuring its replicability (Gobbo \& Russo, 2019; Cuervo-Cazurra et al, 2016; Wolters, 2015).

Table 1: First Round of Exclusion Numbers Based on Document Type in Depth

\begin{tabular}{ll}
\hline Type of Document & Number of Documents \\
\hline Review & 22 \\
\hline Editorial & 4 \\
\hline Book Chapter & 9 \\
\hline Early Access & 10 \\
\hline Reprint & 1 \\
\hline Proceedings & 1 \\
\hline Total & 47 \\
\hline
\end{tabular}

The initial search engine data mining returns 366 manuscripts. The key words that utilized for this step are "gamification" + "higher education". Afterwards, result of the search screened for the dublications. There are not any dublicate entries that are identified during the screening. As a result, eligible number of the papers is stay at 366. As a following step, the author applies the exclusion criteria for literature review, editorial entries, work in progress, reprint, early access or conference presentations and proceedings. This leads to additional omission of 47 papers. After required exlcusions are performed, the available full text number is reduced to 319. As a final screening, the set of non-English and non-open access papers are removed. The final number, as a result, is determined as 137 manuscript. 

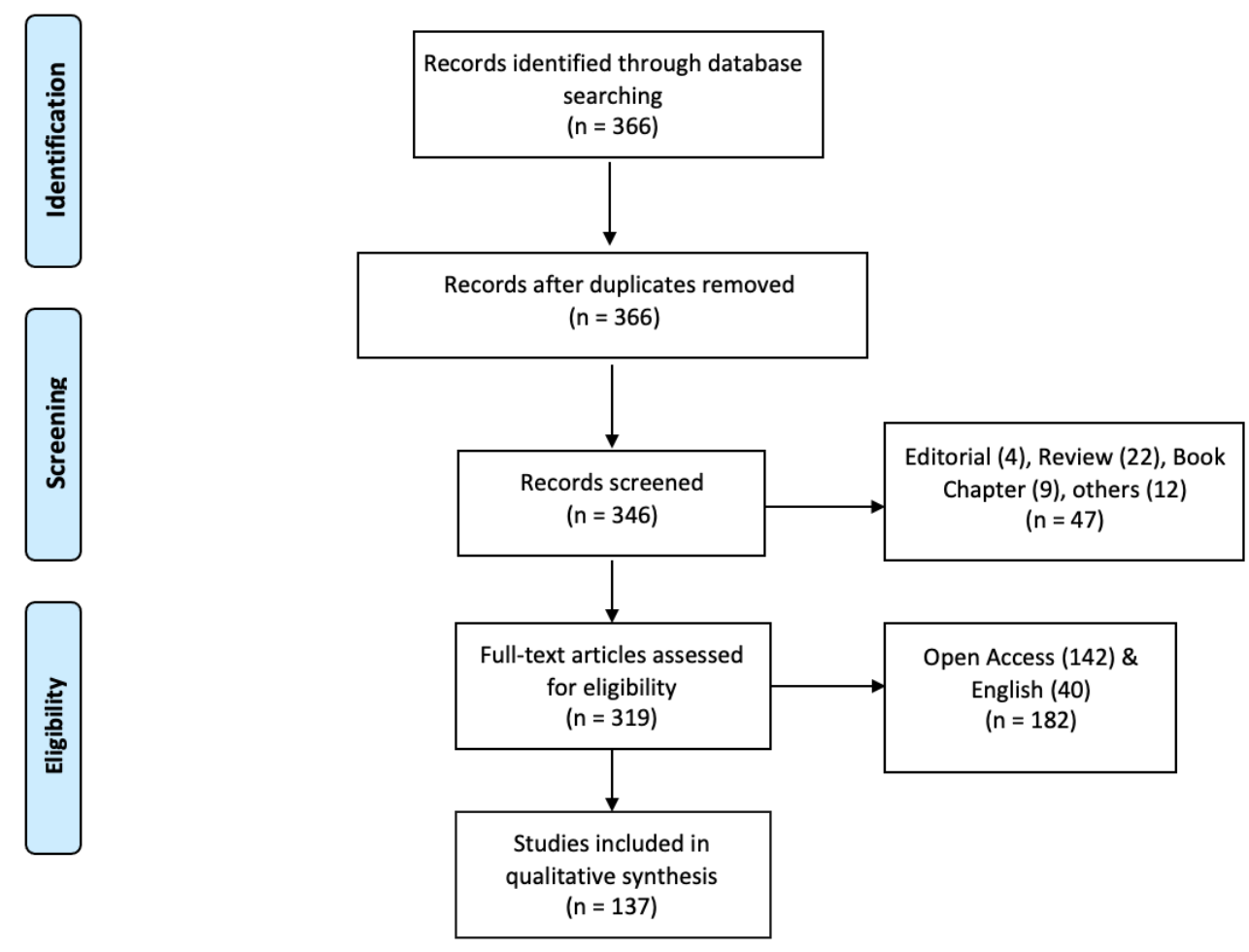

Figure 1: PRISMA Flow Chart

Figure 1 illustrates all the steps employed for the literature review through the flow chart demonstration. It gives a clear understanding of when the exclusions and inclusion criteria are exercised. All the steps mentioned in the flow chart are accompanied by the corresponding total numbers of the studies at a given literature review level for transparency and replicability.

\section{Results}

After examination of the 137 selected manuscripts, one of the most important findings of the systematic literature emerges as the students' favorable point of view towards gamification, especially in online education. For instance, Yang et al., (2020. p.1), report that "predisposition of the students towards the development of innovative didactic experiences based on gamification is corroborated." In addition, Seidlein et al. (2020) suggests that virtual learning platforms that are supported by the gamification learning techniques increase students' information retention, motivation to learn, and revisiting concepts on their own pace, which supports deeper learning among pupils.

Another common theme that approached is the effectivness of the gamification strategies amongst large groups. It is established in the scholarly work that size of a given classroom could alter, negatively or positively, the learning outcome. For instance, Webb \& Palinscar (1996) suggests that certain teaching modes can support large groups and lead to successful learning outcomes; whereas, other strategies may not be as affective (Hmelo-Silver \& Chinn, 2016). However, the conducted literature review highlights that the larger the group either gamification based learning keeps its effectiveness, or, in some casses, it even becomes more effective (Díez-Pascual \& García Díaz, 2020; Ahmad et al., 2020). Students interaction at the large group stimulate more discussions in game settings and in smaller settings, students get more competitive. Therefore, "one size fits all" approach, 
especially in online tools like Kahoot! or similar platforms that supports gamification based teaching, works effectively.

It is also worth to note that findings point a well-design gamification platform could stimulate "implimentation" of previously learnt information into a new platform, digital environment, at a new context. In other words, gamification help students to not only retrieve an information, but also let them to manipulate and leverage in the need of new environments at a practical manner (Carrión-Toro et al., 2020). In a parallel line of thought, the results underline that gamification support students' critical thinking development and competency in problem solving.

In terms of commonly utilized techniques, there are three main gamification strategies emerge. The first strategy is delivering the lecture first, then, asking students to solve a "puzzle" or a "real life alike" scenarios (Karkoub et al, 2020). The second pedagogic usage that emerged as a successful gamifcation strategy is guided problem solving. In this strategy, students expect to work with their groups or standalone to pass different "stages" of a gamified problems via help of pre-designed and mapped feedback system. Every right or wrong decision would tied up with an explanation and feedback. Hence, students can learn at their pace with error and trail approach. The last strategy that widely used is research based approach. In this strategy, the professor would introduce a problem and provide a part of the solution just enough to direct students to conduct their own research. As a result, they would be motivated to utilize as many resources as they can leverage to overcome a gamified challenge.

The final, yet, maybe the most significant finding is gamification strategies' ability to advance learning diagnoses. For instance, Portela (2020, p.29) reports that "this approach is the fact that the student's performance/work generates a lot of useful data to categorise the type of students and understand the best path to success" for higher education puppils. In addition, due to the self-learning, automatic feedack mechanism, and peer-evaluation systems, it reduces the professors' workflow and increase their availability for other scholarly activities as well as university service obligations.

\section{Conclusion}

The ongoing pandemic has shifted how education, teaching strategies, and technology interact with each other. With the universities forced by the COVID-19 to cease on-campus education and immigrate to virtual class settings, virtual tools, once perceived as a supporting or supplementary education aspect, evolve to be the center stone of contemporary education. One of the most widely used and relatively controversial techniques developed as a solution to emergent new higher education trends is gamification. Therefore, this study aims to answer the following three main research questions: (1) Is gamification a viable teaching strategy? (2) What are the commonly used gamification strategies? (3) Can gamification-based teaching be incorporated into online classes?

Through PRISMA systematic literature review, the paper's findings reveal that gamification is a viable teaching strategy and an effective pedagogic style, which can be employed in online and faceto-face classroom settings. It is suitable to utilize at different class sizes as well as various disciplines. Nevertheless, some of the gamification strategies have emerged as more effective than the others due to their ability to support holistic education curricula through their dynamic nature, ability to portray real-life scenarios, and stimulating higher education pupils' epistemological development. These 
gamification strategies are "puzzle/real-life" case studies, "guided problem solving," and "researchbased" gamification approaches.

The literature review findings also highlight that it is possible to establish gamification-based online structures where students can get pre-designated feedback. They will tackle gamification-based challenges step-by-step, either interacting with each other to exchange ideas or individually, and get feedback when they complete each activity or phases. This can stimulate self-paced learning among students and reduce the dependency on course facilitators for feedback. As a result, the time that faculty spend to provide feedback would be reduced, and their workflow potentially gets lighter.

Overall, the study reflects upon; the (1) effectiveness and viability of gamification-based teaching strategies, (2) commonly used gamification techniques ("puzzle/real-life" case studies, "guided problem solving," and "research-based" approaches), and (3) adaptability of the gamification strategies in online teaching settings. Based on the findings, the paper supports the idea that gamification strategies can be leveraged and employed in higher education institutions to meet requisites of the current digital education trends that emerge with the COVID-19.

\section{Limitations and Future Research Opportunities}

This study, like its contemporaries, has its shortcomings. These shortcomings, however, present future opportunities for the researchers. The first shortcoming of the given study is its scope. The literature review is conducted based on a single database and open-access papers. In the future, a research team may leverage multiple databases to establish a broader literature review. The second shortcoming could be seen as the language. Even though the most impactful papers written in English (Gobbo \& Russo, 2019; Wolters, 2015), the study may not address important or impactful studies in other languages. Therefore, it might be very lucrative to form a multilingual team to expand the scope of the study. The third and last shortcoming is that the study based on the publications that are available from the second half of the 2020 and backwards (last five years), which are based on the old-normal state of the gamification strategies employed in higher education. Hence, a study that focuses on recently published articles during the current phase of the pandemic could be a future research opportunity.

\section{Acknowledgement}

The author would like to acknowledge the financial support of Writing Lab, Institute for the Future of Education, Tecnologico de Monterrey, Mexico, in the production of this work.

\section{References}

Aguiar-Castillo, L., Clavijo-Rodriguez, A., Hernandez-Lopez, L., Saa-Perez, D. P., \& Perez-Jimenez, R. (2020). Gamification and deep learning approaches in higher education. Journal of Hospitality, Leisure, Sport \& Tourism Education.

Ahern, A., Dominguez, C., McNally, C., O'Sullivan, J. J., \& Pedrosa, D. (2019). A literature review of critical thinking in engineering education. Studies in Higher Education, 44(5), 816-828.

Ahern, A., O'connor, T., McRuairc, G., McNamara, M., \& O'Donnell, D. (2012, March 08). Critical thinking in the university curriculum - the impact on engineering education. European Journal of Engineering Education, 37(2), 125-132. 
Ahmad, A., Zeeshan, F., Marriam, R., Samreen, A., \& Ahmed, S. (2020, November 27). Does one size fit all? Investigating the effect of group size and gamification on learners' behaviors in higher education. Journal of Computing in Higher Education, 1-32.

Ames, T., Reeve, E., Stewardson, G., \& Lott, K. (2017). Wanted For 21st Century Schools: Renaissance STEM Teacher Preferred. Journal of Technology Education, 28(2), 19-30.

Alomari, I., Al-Samarraie, H., \& Yousef, R. (2019). The Role of Gamification Techniques in Promoting Student Learning: A Review and Synthesis. Journal of Information Technology Education: Research, 18, 395-417.

Archer-Kuhn, B., Wiedeman, D., \& Chalifoux, J. (2020). Student Engagement and Deep Learning in Higher Education: Reflections on Inquiry-Based Learning on Our Group Study Program Course in the UK. Journal of Higher Education Outreach and Engagement, 24(2), 107-122.

Bai, S., Hew, K. F., \& Huang, B. (2020, March). Does gamification improve student learning outcome? Evidence from a meta-analysis and synthesis of qualitative data in educational contexts. Educational Research Review, 30, 1-20.

Bakhanova, E., A. Garcia, J., Raffe, L. W., \& Voinov, A. (2020). Targeting social learning and engagement: What serious games and gamification can offer to participatory modeling. Enviornmental Modelling \& Software, 134, 1-15.

Berryman, M., SooHoo, S., Nevin, A., Barrett, T., Ford, T., Nodelman, J. D., . . Wilson, A. (2013). Culturally responsive methodologies at work in education settings. International Journal for Researcher Development, 4(2), 102-116.

Bogost, I. (2011, August 9). Gamification Is Bullshit. Retrieved February 2, 2021, from The Atlantic: https://www.theatlantic.com/technology/archive/2011/08/gamification-is-bullshit/243338/

Bradley, J. M., Seidman, R. H., \& Painchaud, S. R. (2011). Saving Higher Education. Hoboken, New Jersey, United States of America: Jossey-Bass.

Carrión-Toro, M., Santorum, M., Acosta-Vargas, P., \& Aguilar, J. (2020). iPlus a User-Centered Methodology for Serious Games Design. Appled Sciences, 10(24).

Cuervo-Cazurra, A., Andersson, U., Brannen, M. Y., Nielsen, B. B., \& Reuber, A. R. (2016, July 21). From the Editors: Can I trust your findings? Ruling out alternative explanations in international business research. Journal of International Business Studies, 47, 881-897.

Danka, I. (2020). Motivation by gamification: Adapting motivational tools of massively multiplayer online role-playing games (MMORPGs) for peer-to-peer assessment in connectivist massive open online courses (cMOOCs). International Review of Education, 66, 75-92.

DeMillo, R. A. (2015). Revolution in higher education : how a small band of innovators will make college accessible and affordabl. 2015, Massachusetts, United States of America: The MIT Press.

Díez-Pascual, A. M., \& García Díaz, M. P. (2020). Audience Response Software as a Learning Tool in University Courses. Education Sciences, 10, 1-19.

Eggers, D. W., Hagel, J., \& Sanderson, O. (2012, September 21). Mind the (Skills) Gap. Harvard Business Review.

Gobbo, F., \& Russo, F. (2019). Epistemic diversity and the question of Lingua France in science and philosophy. Foundations of Science, 1-26.

Hallinger, P. (2013). A Conceptual Framework for Systematic Reviews of Research in Educational Leadership and Management. Journal of Educational Administration, 51(2), 126-149.

Hmelo-Silver, C. E., \& Chinn, C. A. (2016). Collaborative Learning. In L. Corno, \& E. M. Anderman, Handbook of Educational Psychology (Third Edition ed., pp. 323-337). New York, United States of America: Routledge.

Jurgelaitis, M. C. (2019). Implementing gamification in a university-level UML modeling course: A case study. Computer Applications in Engineering Education, 27(2), 332-343. 
Kamsker, S., Janschitz, G., \& Monitzer, S. (2020). Digital Transformation and Higher Education: A Survey on the Digital Competencies of Learners to Develop Higher Education Teaching. International Journal of Business Education(160), 22-41.

Kapp, K. M., Blair, L., \& Mesch, R. (2013). The Gamification of Learning and Instruction Fieldbook: Ideas into practive. Hoboken, New Jersey, United States of America: Wiley.

Karkoub, M., Yang, C.-L., Karkoub, W., \& Raslan, M. (2020). Undergraduate Cross-Class Research Projects for Deep Learning in Engineering Education. Advanes in Engineering Education, 8(2), $1-28$.

Klock, A. C., Gasparini, I., Pimenta, S. M., \& Hamari, J. (2020). Tailored gamification: A review of literature. International Journal of Human-Computer Studies, 144, 1-22.

Kotter, J. P. (1996). Leading Change: An Action Plan from the World's Foremost Expert on Business Leadership. Boston: Harvard Business School Press.

Lane, E. J. (2015). Higher Education Reconsidered: Executing Change to Drive Colletive Impact. Albany: SUNY Press.

Levitt, H. M. (2020). Reporting a Qualitative Meta-Analysis: Key Features. In H. M. Levitt, Reporting Qualitative Research in Psychology: How to Meet APA Style Journal Article Reporting Standards (VII ed., pp. 161-183). Washington, DC, United States of America: American Psychological Association.

Lewis, V. (2017). ntegrated internationalism" in UK higher education: Interpretations, manifestations, and recommendations. Doctoral Thesis.

Lizandra, J., Valverde-Esteve, T., \& Garcia-Masso, X. (2020). Use of mobile devices as a facilitator of the practice of physical activity in physical education lessons: experience in higher education. Journal of Physical Education and Sport, 20(6), 3629-3634.

Mainon, E. P. (2018). Leading Academic Change : Vision, Strategy, Transformation. Sterling: Stylus Publishing, LLC.

Mertz, M., Strech, D., \& Kahrass, H. (2017). What methods do reviews of normativeethics literature use for search, selection, analysis, and synthesis? In-depth resultsfrom a systematic review of reviews. Sysematic Reviews, 6, 1-12.

Moher, D., Liberati, A., Tetzlaff, J., Altman, G. D., \& Group, T. P. (2009). Preferred Reporting Items for Systematic Reviews and Meta-Analyses: The PRISMA Statement. PLOS Medicine, 6(7), 1-6.

Naimpally, A., Ramachandran, H., \& Smith, C. (2012). Lifelong Learning for Engineers and Scientists in the Information Age ( $1^{\text {st }}$ Edition ed.). London: Elsevier.

Nolan, R., \& Hunter, F. (2012). The SAGE Handbook of International Higher Education. In D. K. Deardorff, d. H. Wit, J. D. Heyl, \& T. Adams, The SAGE Handbook of International Higher Education (pp. 131-146). Thousand Oaks: SAGE Publications, Inc.

Oliver, E. (2017). Gamification as transformative assesment in higher education. Theological Studies, $73(3), 1-15$.

Panis, I. C., Setyosari, P., Kuswandi, D., \& Yuliati, L. (2020). Design Gamification Models in Higher Education: A study in Indonesia. International Journal of Emerging Technologies in Learning, 15(12), 244-255.

Portela, F. (2020). TechTeach-An Innovative Method to Increase the Students Engagement at Classrooms. Information, 11, 1-31.

Ruano-Borbalan, J.C. (2019). Innovation in higher education: Actors, policies and pedagogical effects. European Journal of Education, 54(4), 493-498.

Sailer, M., \& Sailer, M. (2021). Gamification of in-class activities in flipped classroom lectures. British Journal of Educational Technology, 52(1), 75-90. 
Sasere, O. B., \& Makhasane, S. D. (2020). Global Perceptions of Faculties on Virtual Programme Delivery and Assessment in Higher Education Institutions during the 2020 COVID-19 Pandemic. International Journal of Higher Education, 9(5), 181-192.

Seidlein, A.-H., Bettin, H., Franikowski, P., \& Salloch, S. (2020). Gamified E-learning in medical terminology: the TERMInator tool. BMC Medical Education, 20, 1-10.

Sezgin, F., \& Sezgin, E. (2019). Assessing the Perceptions of ELT Teachers on a Gamification Tool- A Scale Development. International Journal of Recent Advances in Organizational Behaviour and Decision Sciences, 5(1), 1205-1215.

Toda, M. A., Valle, P. H., \& Isotani, S. (2018). The Dark Side of Gamification: An Overview of Negative Effects of Gamification in Education. In A. Cristea, I. Bittencourt, \& F. Lima, Higher Education for All. From Challenges to Novel Technology-Enhanced Solutions. Maceio: Springer.

Treiblmaier, H., \& Putz, L.-M. (2020, August). Gamification as a moderator for the impact of intrinsic motivation: Findings from a multigroup field experiment. Learning and Motivation, 71.

Tsay, C., Kofinas, A., \& Luo, J. (2018). Enhancing student learning experience with technologymediated gamification: An empirical study. Computers \& Education, 121, 1-17.

Vanduhe, V. Z., Nat, M., \& Hasan, F. H. (2020). Continuance Intentions to Use Gamification for Training in Higher Education: Integrating the Technology Acceptance Model (TAM), Social Motivation, and Task Technology Fit (TTF). IEEE Access, 8, 21473-21484.

Wang, H. T., Riki, T., \& Gerard, G. (2016, April). Corporate Social Responsibility: An Overview and New Research Directions. Academy of Management Journal, 59(2), 534-544.

Webb, M. N., \& Palincsar, A. S. (1996). Group processes in the classroom. In D. Berliner, \& R. C. Calfee, Handbook of Educational Psychology (pp. 841-873). Prentice Hall International.

Wolters, G. (2015). Globalized Parochialism:Consequences of English asLinguaFrancain Philosophy of Science. International Studies in the Philosophy of Science, 29(2), 189-200.

World Economic Forum. (2017, May 24). 3 key steps to making sure your skills stay relevant. Geneva, Switzerland.

Xiong, Y., \& Suen, K. H. (2018). Assessment approaches in massive open online courses: Possibilities, challenges and future directions. International Review of Education, 64, 241-263.

Yang, S., Lee, J. W., Kim, H.-J., Kang, M., Chong, E., \& Kim, E.-m. (2020). Can an online educational game contribute to developing information literate citizens? Computers \& Education, 161.

Zemsky, R., \& Banning, L. (2013). Checklist for Change: Making American Higher Education a Sustainable Enterprise. New Brunswick: Rutgers University Press.

Zhang, B., Robb, N., \& Eyerman, J. (2017). Virtual Worlds and Gamification to Increase Integration of International Students in Higher Education: An Inclusive Design Approach. International Journal of E-Learning \& Distance Education, 32(2), 1-22. 